\title{
Зависимость интенсивности спонтанной люминесценции наностержней ZnO от их длины
}

\author{
(C) А.Н. Грузинцев, А.Н. Редькин, Е.Е. Якимов \\ Институт проблем технологии микроэлектроники Российской академии наук, \\ 142432 Черноголовка, Московская область, Россия \\ E-mail: gran@iptm.ru
}

Поступила в Редакцию 4 апреля 2019 г.

В окончательной редакции 9 апреля 2019 г.

Принята к публикации 9 апреля 2019 г.

\begin{abstract}
Исследовано методами оптической люминесцентной микроскопии влияние длины наностержней оксида цинка (диаметром 500 нм) на модовую структуру и спонтанную люминесценцию в ультрафиолетовой области спектра. Показано, что одиночные наностержни с металлическим зеркалом на одном из торцов имеют всего лишь две-три лазерных моды для малых длин нанорезонаторов 8-30 мкм. Установлена различная величина оптических потерь продольных и поперечных волноводных мод в наностержне $\mathrm{ZnO}$, лежащем на стеклянной подложке. Квадратичную зависимость интенсивности спонтанной люминесценции от длины стержня можно объяснить улучшением оптической добротности $Q$ связанных продольных мод света внутри более длинных стержней (эффект Парселла).
\end{abstract}

Ключевые слова: люминесценция, наностержни, излучательная рекомбинация.

DOI: 10.21883/FTP.2019.08.47999.9130

\section{1. Введение}

В последнее время экспериментально были продемонстрированы [1-4] полупроводниковые лазеры на основе наностержней $\mathrm{GaN}, \mathrm{ZnO}$ и $\mathrm{CdS}$. Было показано, что даже единичный монокристаллический наностержень может работать как лазерный резонатор с одной или несколькими продольными модами генерации. Несколько характерных особенностей делают ансамбли полупроводниковых наностержней перспективными для различных приложений оптоэлектроники. Во-первых, малый размер может легко привести к одномодовому режиму лазерной генерации. Типичный диаметр стержней в диапазоне 20-500 нм и длина 2-40 мкм делают их самыми маленькими лазерами из имеющихся в настоящее время. Во-вторых, большой контраст показателей преломления наностержня и окружающего воздуха дает хорошее канелирование оптических мод и улучшает добротность лазерного резонатора. В-третьих, вертикально растущие на подложке стержни излучают преимущественно вдоль своей оси, что дает возможность использовать на практике ансамбли из множества наностержней [5].

Ограничение света люминесценции в малом геометрическом объеме стержней влияет не только на характеристики вынужденного излучения в режиме лазерной генерации, но и на вероятность спонтанного излучения при малых интенсивностях накачки. Дело в том, что изменение интенсивности люминесценции двухуровневой системы от заселенности верхнего $n_{2}$ и нижнего $n_{1}$ уровня описывается соотношением Эйнштейна [6] только для однородной бесконечной среды:

$$
d I / d t=A n_{2} / \tau+B\left(n_{2}-n_{1}\right) I,
$$

где $I$ - интенсивность люминесценции, $\tau$ - время жизни спонтанной люминесценции, $A$ и $B-$ коэффициенты
Эйнштейна. В реальных объектах конечного размера, неоднородно не только распределение I излучения в пространстве (согласно решению уравнения Максвелла с граничными условиями), но и время жизни $\tau$ спонтанного свечения сильно зависит от формы объекта и положения центра свечения внутри него (особенно для среды малых размеров, сравнимых с размером длины волны света). Время жизни $\tau$ определяется для центра с волновыми функциями начального и конечного состояний $\psi_{i}$ и $\psi_{f}$ из соотношения для вероятности спонтанной люминесценции [7]:

$$
P \propto 1 / \tau \propto \Sigma_{k}\left\langle\psi_{i} / \mathbf{E}_{k} \mathbf{D} / \psi_{f}\right\rangle^{2},
$$

где суммирование ведется по всем возможным модам нулевых электромагнитных флуктуаций $\mathbf{E}_{k}$ излучающего объекта. Пространственное распределение поля флуктуаций также определяется решением уравнения Максвелла для среды с граничными условиями, при условии, что полная энергия света в данной моде равна половине кванта $1 / 2 \hbar \omega$ энергии фотона (по статистике - бозона). Таким образом, внутри наностержня вероятность спонтанной люминесценции может отличаться на много порядков величины на поверхности и оси в зависимости от числа и добротности связанных мод. Временем жизни возбужденного центра свечения можно управлять, помещая его в разные места наностержня или изменяя его длину и толщину. При этом кривые затухания люминесценции должны носить неэкспоненциальный характер, а состоять из множества экспонент для структур с одной или несколькими модами, когда электромагнитное излучение сильно неоднородно. С увеличением геометрических размеров число мод возрастает и происходит усреднение интенсивности нулевых флуктуаций в пространстве. В общем случае для 
светоизлучающих полупроводниковых структур центры свечения (квантовые ямы, точки и т.д.) надо стараться помещать в максимумы оптического излучения для увеличения вероятности излучательной рекомбинации (2).

В настоящей работе исследованы оптические свойства отдельных наностержней оксида цинка с металлическим зеркалом на одном из перпендикулярных торцов. Цель данной работы - методами электронной и оптической микроскопии подробно изучить спектральные характеристики и интенсивность спонтанной люминесценции в полупроводниковых наностержнях $\mathrm{ZnO}$ с одним зеркалом на торце, а также определить влияние длины наностержней на модовую структуру и вероятность излучения при оптической накачке малой мощности, когда в рекомбинации (1) преобладают спонтанные процессы.

\section{2. Эксперимент}

Синтез исследованных наностержней проводили в двухзонном кварцевом реакторе проточного типа [8]. В первую зону (испарения) помещали навеску гранулированного высокочистого цинка $(99.99 \%)$, во вторую зону (синтеза) помещали подложки. В качестве подложек использовали кремний с ориентацией (100). Синтез проводили при пониженном давлении в условиях непрерывной откачки. Давление в реакторе поддерживалось на уровне $10^{3}$ Па. Во время синтеза температура зоны испарения составляла $630^{\circ} \mathrm{C}$, температура зоны синтеза $580^{\circ} \mathrm{C}$. В ходе процесса в первой зоне происходило испарение цинка, пары которого поступали во вторую зону, где смешивались с кислородно-аргоновой $\left(15 \% \mathrm{O}_{2}\right)$ смесью. В результате взаимодействия паров цинка с кислородом происходило осаждение нанокристаллов оксида цинка на подложках. Для синтеза использовали газы марки „ОСЧ“. Газовую смесь подавали в реактор со скоростью 6 л/ч. Расход цинка составлял 30-32 г/ч. Процесс синтеза продолжался 15-20 мин. Согласно данным электронно-микроскопических исследований [8], синтезированные образцы представляли собой ориентированные перпендикулярно к подложке ансамбли четко ограненных (рис. 1) монокристаллических наностержней оксида цинка (диаметром 500 нм) длиной 10-200 мкм в зависимости от времени роста.

Нанесение зеркал на торцы стержней проводили по следующей схеме. Массив наностержней на подложке кремния был ориентирован почти вертикально. Поэтому электронно-лучевое напыление алюминия толщиной 50 нм образовывало хорошее зеркало на верхнем торце стержня. Далее проводилось ультразвуковое стряхивание стержней в воде на подложку из стекла. В результате на подложке получалось множество отдельных стержней различной длины с металлическим зеркалом на одном конце, имеющих перпендикулярный второй торец (рис. 2). Из-за различных показателей преломления воздуха и оксида цинка происходит полное или частичное отражение волноводной моды на данном торце наностержня. Таким образом формируется второе

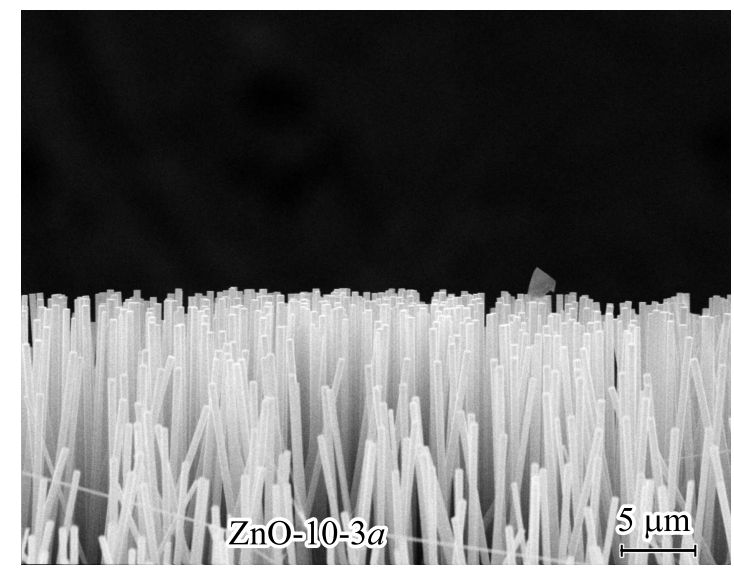

Рис. 1. Электронно-микроскопическое изображение ансамбля вертикальных наностержней оксида цинка.

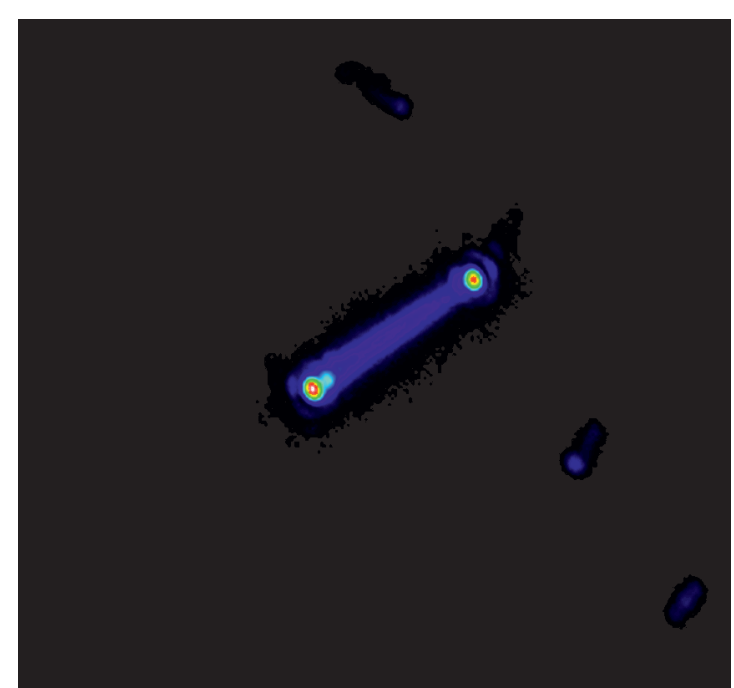

Рис. 2. Изображение в оптическом люминесцентном микроскопе наностержня $\mathrm{ZnO}$ (длиной 16.4 мкм) с зеркалом из алюминия на одном торце.

полупрозрачное зеркало резонатора Фабри-Перо. В результате имеем стержни из оксида цинка длиной от 8 до 200 мкм и диаметром 0.5 мкм с двумя зеркалами на торцах из алюминия и волновода с большим показателем преломления соответственно (рис. 2). Очевидно, что данного рода нанорезонатор имеет гораздо более высокую добротность по сравнению с простым наностержнем с перпендикулярными торцами [5]. В такого рода резонаторе при излучении полупроводника происходит формирование связанных фотонных мод внутри стержня. Конечно, добротность не будет очень высокой и рано или поздно излучение выходит из полупрозрачного конца наностержня. Для регистрации именно излучательных мод мы использовали метод оптической люминесцентной микроскопии при комнатной температуре. 
Спектры фотолюминесценции (ФЛ) регистрировались при возбуждении третьей гармоникой неодимового лазера с длиной волны 355 нм, длительностью импульca 7 нс и энергией в импульсе 1.4 мДж. Возбуждение носило межзонный характер, а фокусирование лазера в пятно диаметром 500 мкм с набором поглотителей позволяло получать плотность мощности возбуждения от $1 \mathrm{KBT} / \mathrm{cm}^{2}$ до $5 \mathrm{MBT} / \mathrm{cm}^{2}$. Люминесценция образца собиралась перпендикулярно к поверхности подложки короткофокусным объективом оптического микроскопа и анализировалась с помощью спектрометра и многоканального CCD детектора. Пространственное разрешение этой системы было не хуже 1 мкм. Измерения спектров проводились при комнатной температуре $300 \mathrm{~K}$. Спектральное разрешение во всех измерения было не хуже 0.05 нм. Морфология наностержней оксида цинка исследовалась также в сканирующем электронном микроскопе Jeol-2000.

\section{3. Результаты и обсуждение}

Прежде всего следует отметить, что ультразвуковое стряхивание стержней из ансамбля приводило к осаждению на стеклянной подложке одиночных наностержней $\mathrm{ZnO}$ с алюминиевым зеркалом на торце различной длины. Это связано с тем, что перелом стержня может произойти в любом месте и, возможно, даже не один раз. В результате на подложке могут появляться часть стержней вообще без алюминия на конце. Однако такого рода образцы легко видны и могут быть идентифицированы в люминесцентном микроскопе по интенсивности свечения торцов. Как правило, свободный (без зеркала) торец светит гораздо интенсивнее всего остального объема стержня и покрытого алюминием торца. Для исследования были выбраны различные по длине наностержни. При этом максимальная длина составляла 140 мкм, что позволяло через оптический микроскоп возбуждать люминесценцию всего стержня (диаметр пятна 500 мкм), но произвести анализ сигнала свечения с каждого из торцов в отдельности (анализируемая область сигнала 30 мкм). Характерные по форме спектры люминесценции наностержня $\mathrm{ZnO}$ (длиной 17.5 мкм) с зеркалом на торце приведены на рис. 3 для разных интенсивностей возбуждения соответственно. Спектры представляют собой довольно широкие полосы спонтанной экситонной люминесценции с максимумом 382 нм при малых ин-

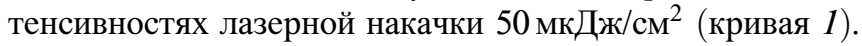
Лишь для интенсивности более 240 мкДж/см ${ }^{2}$ начинает проявляться вклад стимулированного свечения в виде узкой полосы с максимумом 386 нм (рис. 3, кривая 4). При дальнейшем увеличении интенсивности накачки появляется вторая мода стимулированного лазерного излучения с максимумом 384 нм (рис. 3, кривые 6 и 7).

При мощной накачке хорошо различима для всех образцов тонкая модовая структура лазерного спектра с шириной линии порядка одного нанометра. Удивительно, что число этих линий довольно небольшое и

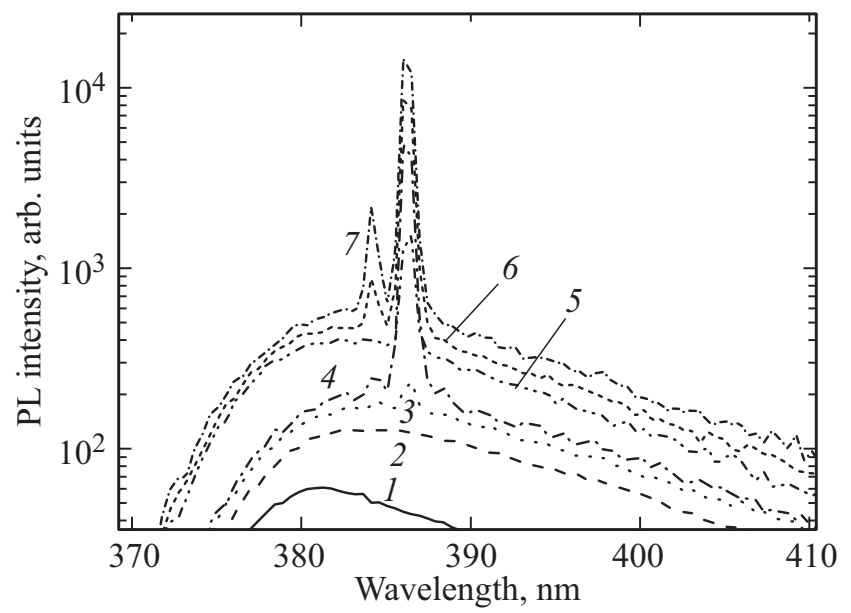

Рис. 3. Спектры фотолюминесценции наностержня $\mathrm{ZnO}$ (длиной 17.5 мкм) при различной интенсивности возбуждающего

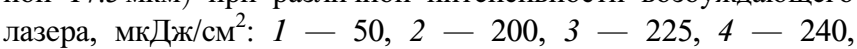
$5-300,6-370$ и $7-550$. Температура измерений $300 \mathrm{~K}$.

логично предположить, что в данном случае лазерная генерация возникает только на продольных волноводных модах наностержней $\mathrm{ZnO}$ с почти нулевым волновым вектором, перпендикулярным оси стержней (нулевая мода). Это легко понять, если учесть более слабую локализацию в стержне излучения поперечных мод с ненулевым орбитальным моментом. В результате этого часть излучения волноводных мод данного типа проникает в подложку из стекла, которое довольно сильно поглощало ультрафиолетовое краевое свечение оксида цинка. Поэтому усиление на данных модах было слабее, чем на продольных, и лазерной генерации на них не возникало. Зная спектральное положение линий продольных мод из формулы для резонатора Фабри-Перо, можно определить длину оптического резонатора из двух зеркал на торцах стержня:

$$
L=\lambda_{1} \lambda_{2} /\left(2 n\left(\lambda_{2}-\lambda_{1}\right)\right),
$$

где $L$ - длина наностержня, $n=2.05-$ показатель преломления оксида цинка на длине волны краевого свечения, $\lambda_{2}=386$ нм и $\lambda_{1}=384 \mathrm{Hм}-$ спектральное положение соседних лазерных мод, взятое из кривой 7 (рис. 3) свечения при максимальной мощности лазерной накачки. Для данного случая расчет по формуле (3) дает значение длины нанорезонатора 18.1 мкм, что хорошо совпадает (с точностью до 1 мкм) с данными по оптической микроскопии.

На рис. 4 представлены спектры люминесценции при минимальной интенсивности накачки 50 мкДж/см ${ }^{2}$ для различной длины стержней. В спектрах преобладает свечение свободных экситонов с максимумом при 382 нм независимо от длины стержней. Однако интенсивность экситонной люминесценции зависит от длины наностержня $\mathrm{ZnO}$. Согласно соотношению Эйнштейна (1), для столь малых интенсивностей люминесценции в ней преобладает спонтанная составляющая. 


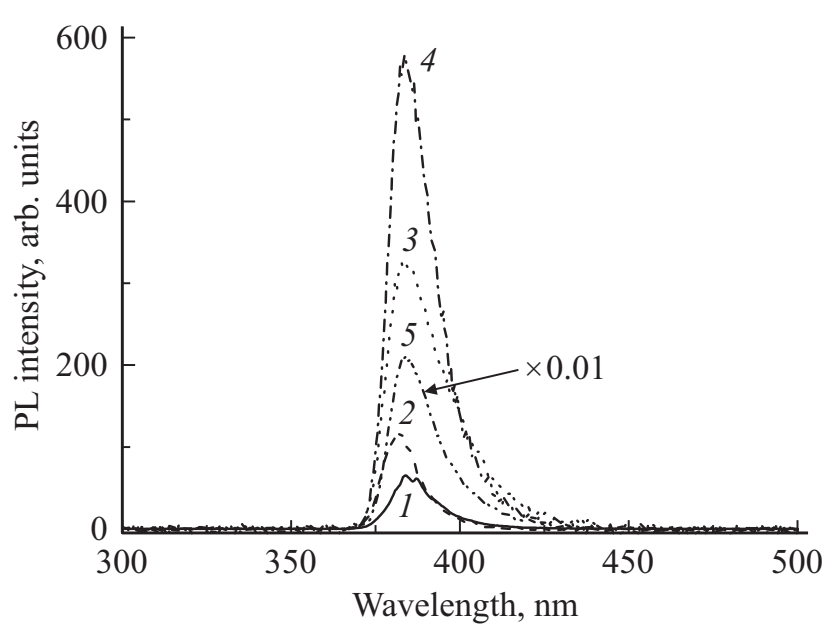

Рис. 4. Спектры фотолюминесценции наностержней $\mathrm{ZnO}$ при

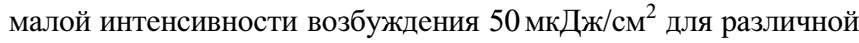
длины стержней, мкм: $1-8.3,2-11.5,3-17.5,4-23.7$ и $5-140$. Температура измерений $300 \mathrm{~K}$.

Вероятность спонтанной люминесценции определяется интегралом (2), который для связанных оптических мод можно в упрощенном виде представить в виде фактора Парселла. Согласно эффекту Парселла для локализованных резонансных мод, вероятность их излучения пропорциональна фактору Парселла [9]:

$$
F_{\mathrm{P}}=3 /\left(4 \pi^{2}\right)(\lambda / n)^{3}(Q / V),
$$

где $\lambda$ и $n-$ длина волны и показатель преломления для излучаемого света, $Q$ и $V$ - добротность и пространственный объем локализованной моды. Последний множитель в этой формуле дает как раз квадрат амплитуды усредненного по объему моды электромагнитного поля вакуумных флуктуаций. Чтобы получить интенсивность люминесценции нулевой моды наностержня оксида цинка, надо вероятность (4) умножить на объем излучающей среды $V$. Таким образом, интенсивность спонтанного свечения в первом приближении пропорциональна добротности связанной моды $Q$. Как мы видели (рис. 3) выше, в нашем случае наибольшей добротностью обладает продольная мода, на которой и происходит лазерная генерация наностержней. Эта добротность равна числу процессов полного внутреннего отражения света на стенках наностержня, перед тем как он покинет стержень через его торец или $Q \sim(L / D \operatorname{ctg} \varphi)^{2}$ (где $L$ и $D$ - длина и диаметр наностержня, а $\varphi-$ угол падения света на стенку). В наших измерениях (рис. 4) спектров спонтанной люминесценции толщина всех стержней $\mathrm{ZnO}$ была одинаковой $D=500 \mathrm{Hм}$, а варьировалась их длина от 8.3 до 140 мкм.

Для подробного изучения зависимости спонтанного свечения наших стержней от их длины мы поочередно анализировали в оптическом микроскопе люминесценцию различных одиночных стержней при мощности

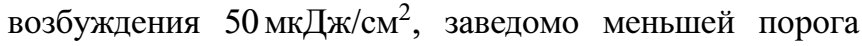

лазерной накачки (рис. 3 и 4). При этом согласно изображению в микроскопе можно было с точностью до одного микрометра определить длину исследуемого стержня. Хорошо различим для всех образцов при комнатной температуре спектр свободных экситонов с шириной линии $\sim 30$ нм. Видно также нелинейное увеличение интенсивности свечения от длины наностержней. На рис. 5 приведена зависимость интенсивности спонтанного экситонного сечения от длины стержней для малых интенсивностей накачки (кривая 1). Полученная экспериментальная зависимость хорошо аппроксимируется квадратичной зависимостью (кривая 2) добротности нулевой связанной моды от длины. Можно предположить, что время затухания спонтанного свечения также будет определяться с учетом фактора Парселла (4) или обратно пропорционально длине стержней оксида цинка. Здесь речь идет об усредненном времени, так как в пучностях связанной моды оно будет меньше, а в узлах - больше. Вообще для структур нанометрового и субмикронного размеров из-за малого числа оптических мод и неоднородного электромагнитного поля временнб́е зависимости спонтанной люминесценции имеют сложный интегральный характер и исследовать их не имеет смысла. Тем более что общее время затухания фотолюминесценции зависит не только от времени излучательной рекомбинации, но и от времени безызлучательной рекомбинации экситонов.

Из изображения в люминесцентном микроскопе (рис. 2) видно, что практически все выходящее спонтанное и лазерное излучение происходит с торцов стержня и его возможно собрать линзой в параллельный пучок, что важно для практических применений. Самая интенсивная мода излучается в основном вдоль оси стержней. Теперь остановимся подробнее на форме и спектральном положении контура усиления или спонтанного свечения нанокристаллов-стержней ZnO. Co-

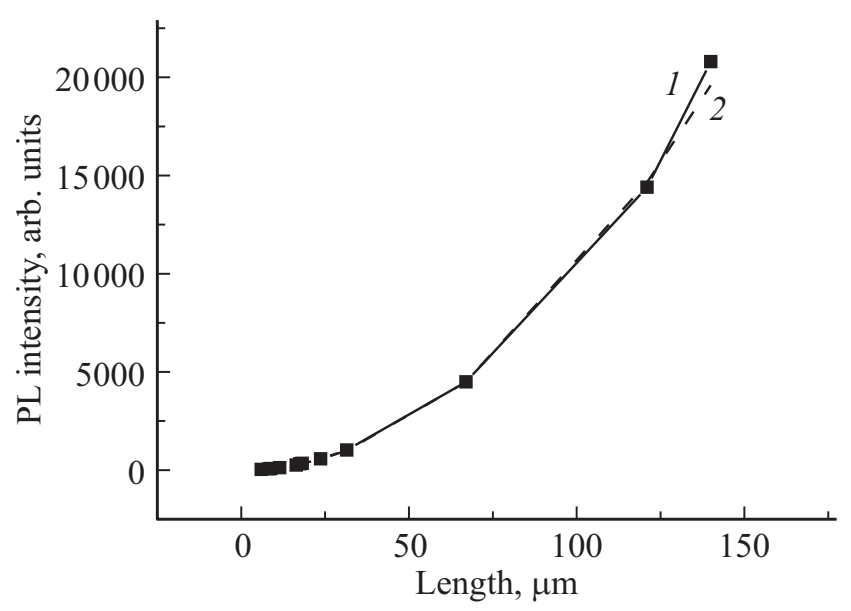

Рис. 5. Зависимость интенсивности спонтанного краевого свечения наностержней $\mathrm{ZnO}$ от их длины в мкм при малой интенсивности 50 мкДж/см² лазерной накачки $(1)$ в сравнении с квадратичной теоретической зависимостью (2). Температура измерений $300 \mathrm{~K}$. 
гласно литературным данным [8] и нашим предыдущим исследованиям $[4,10]$, краевая спонтанная люминесценция в оксиде цинка возникает либо при рекомбинации взаимодействующих свободных экситонов, либо при рекомбинации электронно-дырочной плазмы (ЭДП). При этом пороговые мощности накачки первого механизма ниже, чем второго. Теоретические расчеты положения линии стимулированной люминесценции взаимодействующих экситонов дают для комнатной температуры максимум в диапазоне $382-386$ нм, а для ЭДП - в диапазоне 395-397 нм [8]. Сравнение этих цифр с нашими экспериментальными данными свидетельствует, что в случае наностержней оксида цинка имеет место спонтанная люминесценция за счет рекомбинации взаимодействующих свободных экситонов. При столкновении и последующей аннигиляции свободных экситонов при комнатной температуре в оксиде цинка возникает так называемая Р-линия излучения, в пределах которой и возникает как спонтанное, так и лазерное УФ излучение. Конкретное положение и число полос генерации, как мы видели выше, определяется длиной нанорезонатора (3) и добротностью оптических мод (4).

Ширина (в нашем случае около 1 нм) лазерной линии наностержня $\mathrm{ZnO}$ зависит от добротности $Q$ оптического резонатора (рис. 3). Если оценивать добротность стержня большого диаметра по простой модели резонатора Фабри-Перо (без учета дифракции на торце), то для материала с показателем преломления 2.05 без металлических зеркал получаем величину, меньшую ста, для наших длин стержней. С учетом малого диаметра и дифракции света на торце стержня без зеркала, коэффициент отражения для некоторых мод может достигать $40 \%$, согласно работе [11], за счет разности показателей преломления оксида цинка и воздуха. Следовательно, отсутствие специальных зеркал на торцах стержня дает плохую обратную связь в оптическом резонаторе и ухудшает его лазерные свойства. Использование металлического зеркала в нашем случае позволило увеличить добротность резонатора до 380 , что является рекордной величиной для стержней оксида цинка нанометрового размера. Более точное описание процессов лазерной генерации в наностержне требует численного решения уравнений Гельмгольца для ограниченной среды с учетом взаимодействия света с материалом подложки. При этом поперечные волноводные моды больше взаимодействуют с подложкой (стеклом), на которой лежит стержень, и поглощаются в ней. Из-за этого число мод в генерации резко уменьшается и мы наблюдаем лишь продольные оптические моды с волновым вектором, почти параллельным оси стержня. Очевидно, что это происходит из-за небольшой разницы показателей преломления стекла и оксида цинка. Для наблюдения всех мод возможно использование подложки из пористого стекла с меньшим показателем преломления и меньшим поглощением ультрафиолетового света. С другой стороны, усиление поперечных волноводных мод всегда будет меньше, чем у продольных, так как большая часть их электромагнитного поля находится вне наностержня, т. е. вне усиливающей среды.

\section{4. Заключение}

С помощью оптического микроскопа были изучены спектры ФЛ одиночных наностержней оксида цинка различной длины, полученных методом газофазного синтеза, с алюминиевым зеркалом на одном из торцов. Были сделаны выводы о механизмах возникновения, модовой структуре и спектрах свечения при разных мощностях возбуждения их спонтанной люминесценции и лазерной генерации при оптической накачке импульсами третьей гармоники неодимового лазера. Показано, что наностержни $\mathrm{ZnO}$ с металлическим зеркалом имеют преимущества по всем параметрам лазерного излучения по сравнению с наностержнями без зеркал. Обладая более узкими линиями излучения, они дают стимулированную люминесценцию в направлении вдоль продольной оси стержней со стороны открытого торца. Анализ механизмов излучательной рекомбинации в процессах фотолюминесценции позволил по длине волны максимумов соответствующих линий определить, что в наностержнях преобладает рекомбинация взаимодействующих свободных экситонов. Измерения интенсивности спонтанной краевой люминесценции образцов разной длины свидетельствуют о влиянии фактора Парселла и интерференции света на поверхности и торцах на спектр свечения наностержней $\mathrm{ZnO}$. Показано, что для данных размеров наностержней $\mathrm{ZnO}$ длиной порядка 10-100 мкм реализуется квадратичная зависимость интенсивности спонтанной люминесценции от длины. Увеличение диаметра стержней очевидно приведет к многомодовому режиму более длинных стержней. В этом случае становится возможным излучение в многомодовом режиме, аналогичном стандартному объемному свечению, когда интенсивность пропорциональна объему материала, т. е. длине стержней.

Установлено, что формирующиеся в процессе роста наностержни оксида цинка имеют эффективную стимулированную УФ люминесценцию свободных экситонов при комнатной температуре и являются перспективными для создания коротковолновых направленных одномодовых лазерных источников света. Для дальнейшего улучшения параметров генерации возможен синтез по предложенному методу резонаторов-наностержней оксида цинка на металлической подложке с двумя металлическими зеркалами, коэффициент отражения которых зависит от толщины нанесенного сверху металла.

\section{Финансирование работы}

Работа выполнена в рамках государственного задания № 075-00475-19-00.

\section{Конфликт интересов}

Авторы заявляют, что у них нет конфликта интересов. 


\title{
Список литературы
}

[1] A.N. Gruzintsev, G.A. Emelchenko, A.N. Redkin, V.T. Volkov, E.E. Yakimov, G. Visimberga. Semiconductors, 44, 1217 (2010).

[2] B.P. Zhang, N.T. Binh, Y. Segawa, Y. Kashiwaba, K. Haga. Appl. Phys. Lett., 84, 586 (2004).

[3] T. Hirai, Y. Harada, S. Hashimoto, T. Itoh, N. Ohno. J. Luminesc., 112, 196 (2005).

[4] A.N. Gruzintsev, G.A. Emelchenko, A.N. Redkin, V.T. Volkov, E.E. Yakimov, G. Visimberga. Semiconductors, 44, 1235 (2010).

[5] H.C. Hsu, C.Y. Wu, W.F. Hsieh. J. Appl. Phys., 97, 064315 (2005).

[6] Ф. Качмарек. Введение физику лазеров (М., Мир, 1981).

[7] Л.Д. Ландау, Е.М. Лифшиц. Квантовая механика (М., Наука, 1974).

[8] A.N. Gruzintsev, A.N. Redkin, G.A. Emelchenko, C. Barthou, P. Benalloul. J. Opt. A: Pure Appl. Opt., 8, S148 (2006).

[9] K.J. Vahala. Nature, 424, 839 (2003).

[10] A.N. Georgobiani, A.N. Gruzintsev, E.E. Yakimov, C. Barthou, P. Benalloul. Semiconductors, 39, 661 (2005).

[11] A.V. Maslov, C.Z. Ning. Appl. Phys. Lett., 83, 1237 (2003).

Редактор А.Н. Смирнов

\section{The dependence of the spontaneous luminescence intensity in the $\mathrm{ZnO}$ nanorods on their length}

\author{
A.N. Gruzintsev, A.N. Redkin, E.E. Yakimov \\ Institute of Microelectronics Technology Problems \\ of Russian Academy of Sciences, \\ 142432 Chernogolovka, Russia
}

Abstract The influence of length of zinc oxide nanorods (with diameters $500 \mathrm{~nm}$ ) on the modes structure and spontaneous luminescence in the UV spectrum region is investigated by method of optical luminescent microscopy. It was shown, that the single nanorods with metal mirror on one face have only two or three laser modes for the small nanoresonator length $8-30 \mathrm{mkm}$. The different value of optical losses for the longitudinal and transversal optical modes in the $\mathrm{ZnO}$ nanorod on glass substrate is determined. The square-law spontaneous luminescence intensity increasing on the nanorods length can be explained by $Q$-factor increasing of the related light modes in the longer nanorods (Purcell effect). 